\title{
Etica social bajo el signo de la cruz
}

\author{
David Hollenbach, \\ Weston Jesuit School of Theology, \\ Cambridge.
}

La ética social está atravesando hoy una crisis de identidad. En Estados Unidos - y a un nivel superficial-, la crisis se manifiesta en el actual clima de desilusión con respecto a muchos de los programas del Estado de bienestar. Sin embargo, el problema es mucho más profundo que el que, coyunturalmente, se expresa en la opinión pública.

En este artículo quisiera defender la tesis de que, tras la crisis de identidad de la ética social, lo que está en el banquillo es la tradición humanista occidental. Por humanismo entiendo aquí una orientación del pensamiento y de la acción guiada por un compromiso con el bienestar integral de las personas y por la convicción de que esas personas pueden desarrollarse hasta alcanzar tal bienestar.

La duda actual sobre la tradición humanista podría describirse de la siguiente manera: muchos han perdido confianza en nuestra capacidad para desarrollar una normativa de lo que entendemos por "bienestar humano" y otros muchos ya no creen que podamos configurar una sociedad en que a los seres humanos les sea posible desartollarse en la dirección que propone ese bienestar. En la medida en que esto sea cierto, la ética social atraviesa por una crisis de identidad y se ve abocada a un futuro incierto.

Esta crisis del humanismo significa que están ahora saliendo a luz profundos conflictos, latentes desde hace mucho tiempo en la vida social e intelectual de occidente. En efecto, ya en el alborear de la modernidad, René Descartes expresó una de las tensiones de la conciencia modema que está alcanzando ahora su momento crílico. Descartes propuso una filosofía práctica basada, por una parte, en el conocimiento del ser humano de si mismo, y basada, por otra parte, en el gran libro de la naturaleza'. Desde esta perspectiva, el "yo" y el "mundo", concebido

1. René Descartes, Discourse on Method, en Discourse on Method and Mediations, Iraducción de Laurence J. Lafleur, Indianapolis, 1960, p. 8. 
éste mecánicamente, se convirtieron en los polos dialécticos del pensamiento moderno, lo cual ha sido la contribución específica de la modernidad al humanismo. El tema moderno de la "dignidad de la persona humana" surge del giro cartesiano hacia la introversión 2 , pero, al mismo tiempo, la propuesta cartesiana supuso un intento para entronizar al ser humano como "señor poseedor de la naturaleza"3. Y así, como ha señalado Albert Bormann los elementos de predicción y, sobre todo, de control han sido constilutivos del discurso de la moderniJad4.

La incertidumbre sobre la identidad del humanismo occidental y de la ética social en la actualidad se debe a la pérdida simultánea de plausibilidad del "yo" cartesiano y de la ideología del control sobrc la naturaleza que propició el mismo Descartes. El presupuesto de que se puede llegar a dominar la naturaleza, la vida social y la historia por medio del conocimiento se encuentra hoy radicalmente cuestionado.

Al final del siglo $\mathrm{XX}$, la búsqueda de ese dominio aparece cada vez más como una fuerza destructiva, incluso demoníaca. El "yo" cartesiano era una especie de semi-dios y el conocimiento que este "yo" perseguía era el poder sobre la naturaleza y sobre la soledad. De ese modo, la visión cartesiana abrió el camino a una ética social de un determinado estilo. Sugiere que si podemos lograr un nivel de claridad razonable sobre los valores que queremos promover, entonces se trata tan sólo de "poner en práctica" nuestro proyecto. Sin embargo, hoy somos cada vez más conscientes del escaso control que tenemos sobre los acontecimientos, tanto en la sociedad como en el ecosistema natural. Las "cosas", incluso el "destino", parecen dominarnos cada vez más. Todo ello conlleva una especie de crisis de fe, una pérdida de confianza en nuestra capacidad para configurar la vida social de acuerdo a los valores que hemos elegido.

Algunos han calificado de nihilista este espíritu moderno, pero en mi opinión eso sería ir demasiado lejos. Albert Borgmann lo ha expresado como melancolía o taciturnidad de la mentalidad post-moderna. Con ello quiere reflejar la impresión de que, a lo sumo, podemos aspirar a "ir tirando".

Esta auto-desconlianza contemporánea puede ser analizada en sus dimensiones teóricas y práclicas. En el plano teórico, Max Weber, por ejemplo, subrayaba ya en 1918 que la vida intelectual moderna estaba profundamente marcada por una pérdida de confianza en el poder de la razón "grandiosa"s. Si Descartes

2. Charles Taylor, Sources of the Self: The Marking onf the Modern Identity, Cambridge, 1989, p. 152.

3. Descartes, op. cil., po. 45

4. Albert Bormann, Crossing the Postmodern Divide, Chicago, 1992, p. 2.

5. Max Weber. "Science as a vocation", en H. H. Gerth and C. Wright mills (eds.), Freom Max Weber: Essays in Sociology, Nueva York, 1958, p. 148, 155. 
había "desencantado" el mundo natural al concebirlo desde una perspectiva mecanicista, Weber destruyó el encanto del "yo" al relativizar —como científico social- cualquier auto-compresión normaliva, incluida la suya propia. Según Weber, la búsqueda intelectual de la modernidad ha perdido la capacidad para responder a las preguntas últimas sobre el sentido de la vida humana. En el futuro cualquier conocimiento del bien social que podamos olrecer como tal, no "participa de la contemplación de sabios y filósolos sobre el significado del universo", tal como esto se consideró posible en épocas pasadas.

Weber va, pues, más allá de una mera crítica a la metafísica y la religión. Las fuerzas desmitoligizadoras desafían ahora la validez última incluso del proceso mismo de investigación de las ciencias sociales. La cuestión acerca de la verdad o del significado último del trabajo del científico social no puede dilucidarse ya mediante debate intclectual alguno6. Y en última instancia, el problema se resuelve decidiendo cuál es el "demonio" al que se quiere otorgar divinidad funcional en el estilo de vida de cada uno. De este modo, Weber sugiere que las recomendaciones normativas del analista social no son, en último término, menos arbitrarias que los decretos divinos de las religiones antiguas, y quien se dedica al estudio de la realidad social debe aprender a asumir este hecho "como un hombre"7. En otras palabras, hay que renunciar a toda pretensión de que la ética social sea más que una mera descripción de diversas posibilidades sociales. Los juicios normativos sobre lo que constituye la "buena sociedad" se tornan imposibles.

Desde que Weber describió la perplejidad radical que enfrenta el conocimiento cientifico moderno, esto se ha hecho cada vez más manifiesto e impactante. Esta situación ha llevado a un buen número de pensadores contemporáneos a la conclusión de que lo máximo a lo que podemos aspirar en la vida intelectual es a desenterrar fragmentos de significado que, en realidad, no hacen referencia a nada externo o independiente de quienes los encuentran significativos. Tales fragmentos suelen presentarse como certezas sobre lo que es real o verdadero, cuando, en realidad, son tan sólo constructos humanos.

Así, por ejemplo, Richard Rorty sostiene que una "cultura consistentemente ilustrada" serfa aquella en la que no quedara un solo rastro de divinidad, ni bajo la forma de un mundo divinizado, ni bajo la de un yo divinizado. En ella, no sólo las ideas sobre la santidad, sino también sobre la "pasión por la verdad" o la "realización de las más profundas necesidades del espíritu" habrían desaparecido o, cuando menos, habrían sufrido una profunda reinterpretación"B. De acuerdo con estas premisas, ¿qué espacio queda para un humanismo nonnativo?

6. Ibid, p. 152.

7. Ibid., pp. 115-56.

8. Richard Rorty, Contingency, Irony, and Solidarity, Nueva York, 1989, p. 45. 
¿Qué sentido puede tener un ética social normativa?

El escepticismo con respecto a la posibilidad de un conocimiento teórico de lo que constituye el "bien" de la sociedad tiene también consecuencias prácticas. Si lo primario es el deseo, entonces la acción aparece simplemente como una expresión de "poder". Cualquier pretensión de saber lo que constituye el bien social no es, en realidad, más que la afimación de un interés particular, que busca imponerse. Cuando se combinan la pérdida de confianza en nuestra capacidad para conocer cómo deben ser los contornos de una sociedad humana, por un lado, y, por el otro, el impulso moderno por controlarlo todo, entonces la acción es cuestión de "cómo te controlo mejor para servir a mis propios intereses", "cómo nosotros controlamos a los otros en nuestros propios términos".

Esta actitud lleva a una guerra segura, ya sea en un búnker en Berlín, en los despachos de los especuladores financieros, activos en la red electrónica que constituye la aldea global de la economía moderna, o en los "cuarteles" (verdaderas salas de guerra) de las campañas políticas contemporáneas. Si el deseo está por encima de loda norma, el poder se expresará como dominación del fuerle sobre el débil. Así, nuesura época está asistiendo al resurgimiento de una tendencia intelectual bien conocida en la historia del pensamiento, tendencia que apareció en la antigua Grecia con los sofistas y que encontró nueva expresión en los nominalistas de la edad media y de los albores de la edad moderna.

Como con los sofistas y nominalistas del pasado, esta corriente tiende a reducir todas las tareas de la sociedad y de la polis a una cuestión de deseo y de poder. En expresión de Weber, "cuando las palabras se usan para expresar juicios sociales normativos, se convierten en armas arrojadizas. Así utilizadas, las palabras dejan de ser rejas de arado que trabajan el suelo del pensamiento contemplativo; son espadas para combatir enemigos"9. Aquí, Weber recuerda al Trasínaco de la La república de Platón: la justicia es tan sólo la ventaja del más fuerte 10. Y Rorty, en uno de sus estados de ánimo más nietzscheanos, ha escrito que una valoración positiva de la existencia personal es la capacidad de decir al final de mis días: "Eso es lo que yo quise"11. Tal actitud tiene que sospechar, necesariamente, de cualquier aproximación metafísica o filosófica a la ética social. Pero no sólo eso. Socava también cualquier pretensión secular de conocimiento normativo, conocimiento al que todas las sociedades se siguen aferrando, como, por ejemplo, cuando se afirma la existencia de derechos humanos universales. Una sociedad de éxito será, entonces, aquella de cuya historia y política se podrá decir: "Eso es lo que nosolros quisimos".

Quizás estamos exagerando la importancia de este modo de pensar en nues-

9. "Science as a Vocation", p. 145.

10. Republic, p. 338c.

11. Contingency, Irony, and Solidarity, p. 29. 
tro mundo actual, pero, en mi opinión, sería un grave error minusvalơar. su influjo, tanto en el ámbito de la acadernia, como en el de la cultura, tomada esrá en sentido amplio. Su presencia, incluso aunque sólo sea germinalmente, socava la posibilidad misma de una búsqueda intelectual de lo que constituye una sociedad humana o una cultura de valores.

Esa falta de confianza en la posibilidad de superarnos se percibe, aunque sea en forma latente, incluso en los esfuerzos de John Rawls por encontrar un modo de reconciliar visiones diversas - y aun en competencia - sobre el bien social y las correspondientes voluntades en conflicto, mediante una nueva aproximación al contrato social. $Y$ es que la teoría, admirable, pero en última instancia lúgubre, de Rawls recomienda "evitar" las preguntas acerca del bien público y social, si queremos que la vida social tenga alguna posibilidad de ser nínimamente humana. Por tanlo, el postmodernismo intelectual de nuestro tiempo está caracterizado por una actitud de sospecha respecto a cualquier esquema de significado, a cualquier tradición, a cualquier ideología y teoría científica y tecnológica que tenga la pretensión de proporcionar explicaciones totales.

Y con razón. Hay que reconocer que las explicaciones que buscan el control que desea la mente moderna son, en el mejor de los casos, parciales, e incluso corren el peligro de provocar inmensa destrucción cuando se las considera de modo excluyente. ¿Quién puede negar la legitimidad de tales sospechas teniendo en cuenta las sangrientas realidades del siglo XX? La ciencia se ha puesto al servicio de la carnicería genocida de Auschwitz y la destrucción de ciudades enteras como Dresden y Hiroshima. Sicologías concebidas para liberar a las personas de la histeria se han convertido en una especie de auto-conciencia centrada en el interés del propio individuo que amenaza con convertirse en narcisismo socialmente aceptado.

Una ideología político-econónica que habla prometido liberar a los obreros de sus cadenas mandó contra ellos tanques en Budapest, en Praga y en la plaza de Tienanmen, los deportó al gulag, los masacró en los campos de muerte de Camboya, y linalmente expiró sin un quejido al verse confrontada con una revolución de terciopelo lidereada por poetas, obreros de la construcción naval y sacerdotes.

La revitalización de tradiciones que sólo justifican formas limitadas de guerra en caso de causa justa también se ha encontrado en nuestro siglo con una gran sorpresa: de conflictos armados en los que tan sólo el 14 por ciento de las víctimas eran civiles (caso de la primera guerra mundial) hemos pasado a otros, a final de siglo, en los que el porcentaje de mortandad de los no-combatientes se ha elevado al 90 por ciento 12. Visiones religiosas de la "buena" sociedad han contribuido recientemente a que personas inocentes sean víctimas de conflictos

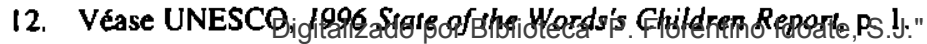

Universidad Centroamericana José Simeón Cañas 
y atrocidades en el Franja Occidental y Gaza, en Belfast y en las ciudades de Africa del Sur, en Argelia, Sudán, Kurdistán y Bosnia.

La sospecha que producen estas experiencias ha llevado a una encrucijada, al final del siglo XX. Tal vez prefiramos abandonarnos al distanciamiento irónico como estrategia de supervivencia y conformarnos con "cambiar de tema" si alguien insiste en preguntar por el fondo del asunto. $O$ quizás decidamos seguir un camino semejante al que llevó a Buda a afirmar que la primera Noble Verdad, aunque no la última, es Dukkha: todo es sufrimiento. dolor, tristeza, miseria. Aquellos que se niegan a recurrir a la ironía para adornecer su malestar pueden decir de nuestro siglo lo que san Agustín dijo de los logros del imperio romano: "no podrás mostrar que los seres humanos vivieron felices, porque sus vidas Iranscurrieron entre horrores de guerra, derramiento de sangre, sangre de enemigos y de amigos, bajo la sombra del miedo y del terror, de ambiciones sin freno. La única alegría a la que se podía aspirar lenía el brillo frágil del cristal, una alegría empañada por el miedo de que en cualquier momento pudiera romperse en mil pedazos 13. Cuando recorreinos, sin pestañear, lo ocurrido en el siglo XX, no es injustificado llegar a la cenclusión, con los poetas y los místicos, de que el mundo está en llamas.

En consecuencia, hacer ética social en el mundo posımoderno exige que nos confrontemos, cara a cara, con lo que clásicamente se ha llamado el "problema del mal". Este es el inexorable tema del final del siglo XX, un desafío que no sólo cuestiona el trabajo de teólogos y filósofos, sino de cualquiera que hoy se siga haciendo las preguntas de Kant: ¿qué puedo saber como cierto? ¿Qué debo hacer? ¿Qué puedo esperar? 14. En el plano de las verdades fundamentales, ¿no es cierto que los seres humanos son hostiles entre sí y no puede extrañarnos que, llegada la ocasión propicia, se manifiesten como tales?

H. Richard Niebuhr explica la destructividad humana como una reacción defensiva ante esa hostilidad percibida. Confrontados con ella, "el tono de nuestras vidas es la ansiedad y la auto-preservación es nuestra ley primera. Por eso dividimos nuestro mundo, parte en bueno y parte en malo, nuestro entomo entre amigos dispuestos a ayudarnos, a mantenernos a flote, y enemigos que intentan reducirnos a seres insignificantes o que incluso pretenden hacernos desaparecer"Is. Pero este esfuerzo por asegurar el yo personal mediante lazos estrechos de amistad o de alianzas políticas de carácter más amplio está condenado al

13. Agustine, The City of God, traduccizon de Henry Bettenson, Londres-Nueva York, 1984, Book IV, cap. 3, p. 138.

14. Critique of Pure Reason, Iraducción de Norman Kemp Smith, Nueva York, 1965, p. 635.

15. The Responsible Self: An Essay in Christian Moral Philosophy, Nueva York, 1963. pp. 140-141. 
fracaso. Y la intensilícación de esfuerzos por lograr dicho objetivo recurriendo a esta estrategia sólo conduce a la búsqueda de un mayor control, el cual no produce sino más hostilidad. la cual, a su vez, genera más injusticia y más violencia.

Así, pues, la cuestión que se oculta tras la crisis que afecta hoy al humanismo es la pregunta de si el misterio que abarca al universo es hostil al ser humano. La raíz de la crisis, en mi opinión, es religiosa y teológica. Esta cuestión se suscita inevitablemente no sólo entre personas que pertenecen a tradiciones religiosas, sino en todo aquel que observe la historia del siglo $\mathrm{XX}$ con los ojos abiertos. Si la vida social está tan deteriorada, que lo único a lo que podemos aspirar es a "ir tirando", la respuesta a la cuestión kantiana acerca de lo que razonablemente podemos esperar se convierte en "de momento, sobrevivir". Y si todo a lo que podemos aspirar es a un respiro de supervivencia temporal, el resultado será "más de lo mismo".

El único modo de detener esta espiral de auto-defensa y agresión, nos sugiere H. Richard Niebuhr, es el descubrimiento de que bajo el conflicto y las rupturas de la vida social existe una presencia sanante y reconciliadora, que asegura nuestra identidad personal allí donde nosotros fracasamos. La posibilidad de un humanismo y de una ética social que sea algo más que un mero "ir tirando" se convierte, de este modo, en la cuestión sobre si existe una presencia última, que merece nuestra conlianza y ante la cual podemos renunciar a nuestros esfuerzos frenéticos por controlarlo todo.

Al finalizar este siglo XX, la cuestión con la que se ve confrontado todo pensamiento crítico, incluido el más secular, es si la realidad última que constituye, fundamenta y engloba la existencia social es hostil o acogedora. Recurriendo de nuevo a una expresión de $\mathrm{H}$. Richard Niebuhr, ¿cuál es la realidad más profunda en el núcleo de nuestro mundo fragmentado y conflictivo? ¿El Dios amigo o el Dios enemigo? El Dios enemigo es el nombre que utiliza Niebuhr para referirse al significado último de la existencia cuando "todo lo que nos sucede lo interpretamos como producto de animosidades o como manifestaciones del imperio de la destrucción"16. Tal interpretación conduce a lo que Niebuhr llama una "ética de la muerte"17, una ética construida sobre el miedo a la muerte y sobre el esfuerzo por evitarla, mediante el empeño por controlar el mundo. Para sostener tal tipo de élica, hay que recurrir, en el fondo, a una "negación de la muerte", que es ilusoria. Pero tales ilusiones, eso parece, sólo pueden ser mantenidas recurriendo a una mentalidad "hypermodernista", es decir, a la hybris moderna por controlarlo todo. llevada a los extremos que hacen

16. Ibid, p. 142.

17. Ibid., pp. 143-144, 176. 
posible las nuevas tecnologías actuales 18. Si ésta es nuestra única opción, estamos asistiendo no sólo al línal del humanismo cristiano, sino de todo humanismo. Y si ćstc es cl caso, nos enfrentamos también al final de todo lo que ha intentado conscguir la ética social.

La alternativa sólo puede consistir en encontrar una última fuente de reconciliación, o, lodavía mejor, de redención. Pero confrontados con la historia del siglo XX, ¿cómo va a ser esto posible? Personalmente quisiera sugerir que sólo a través de una reflexión religiosa y teológica. Insisto en que este reto es una interpelación a todos los que desean desarrollar una ética social, no sólo a quienes intentan poner en diálogo sus convicciones religiosas y la dimensión social de la existencia. Con esto no estoy tratando de conseguir espacios para una ética cristiana de tipo sectario ni estoy defendiendo que la ética social sólo puede existir dentro de la Iglesia. Pienso, más bien, en la posibilidad de una ética social en un mundo pluralista y abierto a muchas opciones religiosas, un mundo que incluye a muchos agnósticos y no creyentes. Y la razón para esta opción es que la cuestión fundamental a la que responde la élica social es precisamente la de cómo deberíamos vivir juntos en este tipo de mundo. Si la respuesta a esta pregunta está basada en la convicción de que la realidad última que lo engloba todo y a todos es la "hostilidad", no tenemos más opción que abordar la vida social con mucha cautela y a la defensiva. ¿Es esto todo a lo que podemos aspirar? Si asi es, nuestras expectativas sociales tienen que ser igualmente minimalistas.

Históricamente, la tradición cristiana ha articulado una respuesta más positiva a esta pregunta, en términos de una teología de la creación que recalca la convicción de que la persona humana ha sido creada a imagen y semejanza de Dios. En muchas aproximaciones teológicas a la ética social, particularmente en las católicas, la razón humana, el entendimiento y la libertad se comprenden como analogías o reflejos de la sabiduría y la libertad divina, $y$, por ello, todo proyecto social razonable es percibido en continuidad con la sabiduría de Dios. Pero si el análisis que hemos hecho es correcto, la respuesta católica tradicional no sería más que "silbidos en un cuarto oscuro para disimular el miedo que produce una liera agazapada tras las sombras". Porque lo que está en cuestión es, precisamente, que la razón humana merezca nuestra confiaza y que la liberlad sea supuestamente buena.

18. Estas liases las he tomado de Ernest Becker. The Denial of Dearh, Nueva York, 1973, pp. 12-19 y de Brogmann, op. cit., pp. 12-19, 78-109. El tratamiento que hace H. Richard Niebuhr de la "ética de la muerte" presenta muchos paralelismos con el análisis del pecado de su hermano Reinhold Niebuhr. Véase Reinhold niebuhr, The Nature and Destiny of Man, 2 vols., Nueva York, 1964, vol. 1, caps. VI y VII. Reinhold Niebuhr y Emest Becker son deudores, ambos, del concepto de angustia de Soren Kierkegaard. 
En un mundo en el que la razón y la libertad del ser humano hah producido las realidades de este siglo XX, hablar de continuidad entre to humeno y lo divino sólo puede significar que el misterio último de la existencia - Dios- no es un Amigo del ser humano sino, más verosímilmente, un Enemigo: Dios crea con el único fin de destruir. Por esta razón, un humanismo fundamentado teológicamente - si es que hoy tal cosa es posible - tiene que argumentar de manera diferente sin presuponer, ingenuamente, la bondad de lo hurnano y encontrar luego la manera de afirmar que Dios sanciona esa bondad. Y precisamente aquí es donde aparece la cruz como necesidad para cualquier visión humanista y para una subsiguiente ética social.

La teología de la cruz ha jugado un papel central en el pensamiento ético cristiano desde san Pablo hasta san Agustín, Lutero y Reinhold Niebuhr. Esta tradición es plenamente consciente de que la bondad de la criatura humana queda distorsionada cuando ésta se esfuerza por negar su condición de criatura. De acuerdo con el Génesis, la dignidad de la persona en cuanto imago Dei se desnaturaliza cuando el ser humano se esfuerza en "ser como Dios". Llevada del orgullo, la arrogancia y el deseo desenfrenado por controlar y dominar, la persona humana tiene una inclinación al mal que lleva a destruir al inocente y al justo, y en última instancia, incluso a Aquel que nos ha regalado el significado y la realidad del amor incondicional. En esa teología, la cruz da testimonio de la distorsión que los seres humanos son capaces de infligir sobre sí mismos, sobre otros y sobre la creación entera. La teología crucis de estos pensadores ha sido usada, en ocasiones, en sentido anti-humanista, como instrumento para recortar las aspiraciones a una forma de vida más humana. Las teologías feministas han puesto de relieve que, en algunas versiones, este modo de pensar puede reflejar una experiencia específicamente masculina, con su peligro de orgullo, y tal vez puede contribuir a minusvalorar los esfuerzos de las mujeres por lograr una personalidad independiente 19.

Pero existe también una interpretación de la cruz que puede conducir a un profundo humanismo, humanismo que tiene raíces suficientemente hondas para resistir el desencanto producido por lo que Weber denominó la razón majestuosa y la desilusión resultante del actuar humano en el siglo XX. Es un humanismo que, de cara a la humanidad, fija sus esperanzas en la convicción de que la compasión, no la maldad, es el atributo último de la única Presencia en medio de las piezas de nuestro mundo fragmentado.

19. Para una idea germinal en esta dirección, véase Valerie Sasiving, "The Human Situation: A Ferninine View", en Carol Christ and Judith Plaskow (eds.), Womanspirit Rising: A Feminist Reader in Teligion, Nueva York, 1979, pp. 25-42. Véase lambien Judth Plaskow, Sex, Sin, and Grace; Women's Experience and the Theologies of Reinhold and Paul Tillich Washolechipgion. 1980. Idoate, S.J."

Universidad Centroamericana José Simeón Cañas 
La cru\% en cfecto. es una invitación a percibir que el misterio último del que están transidas nucstras vidas acoge la finitud humana, incluida la muerte. La fucnte de todo to que existe comparte el sufrimiento humano, incluso la miseria infligida por aquellos que, ilusoriamente, intentan negar la mucrte, recurriendo para ello a mecanismos de control autodefensivo. Según esto, la cruz de Jesucristo no sanciona ningún tipo de autosacrilicio que pacta con la injusticia o la violencia. Por cl contrario, la cruz desvela que en cl corazón del mundo está la misteriosa presencia de Aquel que se compadece radicalmente de todos los que suliren. La cruz es la revelación de la solidaridad divina con todos aquellos que se sienten abandonados y olvidados. En otras palabras, la cruz es el signo preeminente de la amistad y la misericordia divinas.

Tomás de Aquino describía la amistad como la forma de amor más conducente a un corazón compasivo. "Puesto que una persona que ama a otra considera al amigo como otro yo, percibe el dolor de su amigo como suyo propio hasta el punto de que se lamenta por el Jolor de su amigo como si a él misıno le doliera". Tomás aplicó csta concepción de la misericordia directamente a Dios: Dios entra en comunión y solidaridad con la humanidad detrozada sólo a través del amor, amando a los que sufren como a amigos. El atributo primordial de Dios no es otro que la misericordia. Por decirlo así, el corazón de Dios se compadece ante la experiencia de tanto sufrimiento humano, y, en la cruz, ese sulrimiento y Dios mismo sc unen en una unión real20. La cruz es el signo preeminente de esa solidaridad divina. Por lo tanto, el signo de la cruz es una invitación a interpretar el último misterio de la historia humana como amistad compasiva, como solidaridad radical con las víctimas de nuestro mundo hypermoderno21. Este Dios puede ser llamado Amigo, incluso al final del siglo $\mathrm{XX}$.

El signo de la cruz abre la posibilidad de una ética de la solidaridad compasiva. Esla élica cstá ya anticipada y encuentra analogías en varias teorías morales seculares de carácter filosófico. David Hume y Adam Smith consideraron la simpatía, la compasión, como el requisito esencial de la moralidad social. Rawls hace de "la ventaja del menos aventajado" uno de los principios fundamentales de la justicia. Rorty y Judith Shklar abogan por una ética cuya orientación básica sea evitar infligir dolor y tratar de aliviar el sufrimiento. En todas estas aproximaciones a una ética social resuena la invitación del signo de la cruz. Pero Smith halló un modo de combinar la "simpatía" con la aceptación entusiasta del sistema de mercado libre, mercado que con demasiada frecuencia escupe al pobre en el rostro. Rawls, en su trabajo más reciente, ha reconocido que la defensa del liberalismo político podría exigir que a los menos afortunados no se

20. Summa Theologiae, II-II, q. 30, art. 2.

21. La frase "solidaridad con las víctimas" es de Matthew lam. Véase su Solidarity with Victims; Toward a Theology of Social Transformation, Nueva York, 1982. 
les garantice el lugar central que tenían en su Theory of justice. La llamada de Rorly a la solidaridad con los que sufren está transida de distanciamiento irónico, que provoca espontáneamente la pregunta: “estás hablando en serio?”.

Cada uno de cstos planteamientos ofrece fragmentos y pistas para una ética social bajo el signo de la cruz. Sin embargo, todos ellos dejan preguntas sin plantear y otras sin responder, preguntas con las que nos confronta la cruz. ¿Qué significado tiene la compasión, la justicia en favor de los pobres o la solidaridad, cuando, por lo que podemos constatar, ninguna de ellas consiguc sanar estc mundo'? Por si esto fuera poco, lodas esas posturas éticas son extrapolaciones de un egocentrismo o egoísıno ilustrados. Cuando se exige desde cllas coherencia personal o políticas sociales que desafíen el interés particular de los individuos, no debiera sorprender que todas muestren debilidad $\mathrm{e}$ inconsistencia. $\mathrm{Y}$ cs que todas ellas guardan silencio sobre el contexto más amplio, que es el que ofrece sentido último a la solidaridad y a la compasión. Es cierto que estas posturas éticas apuntan hacia dicho contexto y atisban un posible significado más profundo de la solidaridad compasiva. Incluso es razonable sospechar que se inspiran más en el amor simbolizado en la cruz que en la dialéctica de Platón o en la razón pura de Kant22, y por eso las considero aliadas de la posición que intento defender en este artículo. Pero cuando de los atisbos de significado que éstas contienen se pasa a la conmoción que representa la cruz, entonces es cuando se perfila con nitidez una ética social bajo el signo de la cruz²3.

Es ésta una ética que renuncia al intento de construir el sentido de lo moral como exlensión de la supervivencia lemporal del yo moderno y se pone en manos de un Amigo compasivo que nos salva cuando nosolros hemos fracasado en nuestro intento por lograr la salvación por nosotros mismos. Dicha renuncia —dicha fe- puede generar compasión activa, tal como Hume, Rawls y Rorty intentan fundamentar, empeño en el que, en mi opinión, sólo logran un éxito parcial. Una teología de la cruz, así entendida, es fuente de un activo esfuerzo contra las realidades que generan sufrimiento, y no de pasividad ante el mal o ante un status quo opresivo. En este sentido es muy revelador el trabajo de mi amigo el jesuila Ignacio Ellacuría.

Ellacuría, como ustedes saben bien, fue uno de los seis jesuitas asesinados por los militares en El Salvador, el 16 de noviembre de 1989. Su muerte fue resultado directo de su solidaridad activa con los pobres, de su lucha en favor de

22. Véase Richard Rorty, "The Seer of Prague", en Review of three works by the Czech philosopher Jan Patocka, new republic, julio, 1991, p. 40.

23. Para laa discusión sobre el reconocimiento, tanto parcial como pleno, del significado de un símbolo religioso como la cruz, véase David Tracy, Plurality and Ambiguity: Hermeneutics, Religion, Hope, San Francisco, 1987, cap. 5, esp. pp. 109-111.q 
la justicia y de su compromiso por superar el estado de guerra civil violenta24. Todo la actividad intelectual y toda la praxis de Ellacuría fue un poderoso esfuerzo por dar respuesta al mundo actual, un mundo en el que una gran mayoría de la humanidad está "Jiteral e históricamente crucificada por opresiones naturales y, sobre todo, por opresiones históricas y personales"25. Para Ellacuría, tanto el significado de la vida histórico-social como el de la cruz de Jesucristo se hacen patentes en la vida de ese pueblo crucificado. Hoy, la solidaridad con el sufrimiento de los pobres y oprimidos es una dimensión esencial del significado práclico de la cruz de Cristo en medio del mundo. La muerte de Jesús fue la consecuencia del conflicto entre su activa proclamación de la solidaridad del reino de Dios y un poder idolátrico que representa la antítesis de dicha solidaridad.

Ellacuría fue un filósofo y pensador social de considerable sofisticación. Su compromiso humanista lo llevó a hacer uso de todos los recursos de la reflexión racional y del análisis social a disposición de un profesor y rector de universidad. Pero, al mismo tiempo, esta theologia crucis le exigía poner todos esos recursos al servicio de su empeño fundamental: lograr una comprensión más profunda del sufrimiento y un modo más eficaz de combatirlo. Desde este tipo de humanismo, escribió que "la razón y la le se funden al confrontarse con la realidad de los pobres. La razón ha de abrir sus ojos al hecho del sufrimiento. La fe ve en los débiles de este mundo el triunfo de Dios, lo cual es para muchos que no la tienen un escándalo, porque en los pobres nosotros percibimos el significado auténtico de la salvación y de la conversión a la cual hemos sido llamados"26. Ellacuría, sin embargo, nunca se hizo ilusiones de que sólo los recursos intelectuales le posiblitarían a él y a sus colegas de la Universidad Centroamericana controlar los acontecimientos en El Salvador. De hecho, había predicho que la solidaridad con los que sufren podía llevar al destino de Jesús. En tal destino podría participar todo el que se dedicase a la tarea de desclavar y bajar a los crucificados de la cruz27. Y, como sabemos, esta predicción se vio brutalmente confirmada en su muerte sangrienta y en las de sus compañeros.

24. La mejor exposición de los acontecimientos que llevaron a estos asesinatos y de los esfuerzos subsiguientes para lograr la impunidad para los culpables puede verse en martha Doggett, Una muerte anunciada. El asesinato de los jesuitas en El Salvador, San Salvador, 1994.

25. Ignacio Ellacuría. "El pueblo 'crucificado", en Ignacio Ellacurfa y Jon Sobrino (eds.). Mysterium Liberatioms: Conceptos fundamentales de la Teología de la $\mathrm{L}$ beración II, San Salvador. 1990, p. 189.

26. "The task of a Christian University", en Sobrino, Ellacurfa et al, Companions of Jesus: Jesuit Martyrs of El Salvador, Nueva York, 1992, pp. 149-150.

27. Véase Jon Sobrino, El principio misericordia: bajar de la cruz a los pueblos crucificados, San Salvador, 1192, esp. el capítulo 4, "Los pueblos crucificados, actual siervo sufriente de Yahvé", ensayo dedicado a la memoria de Ignacio Ellacuría. 
La conclusión es que una ética bajo el signo de la cruz nos pide que abramos nuestros ojos al sufrimiento del mundo actual, nos mueve a una mayor solidaridad con los que sufren y nos lleva a trabajar por aliviar este sufrimicnto y por superar sus causas. Estamos ante la radicalización de la postura élica a la que apuntan la "compasión" de Hume, el "principio de diferencia" de Rawls y la llamada de Habermas que nos invita a incluir las voces de los marginados en el discurso social.

Tal ética está presta a asumir los riesgos de esta solidaridad en la acción porque, para aquellos que tienen ojos para ver, la cruz revela que el misterio último que impregna la vida no es otro que la Amistad salvífica. Rcmitir al más específico de los símbolos cristianos - la cruz- puede sonar a negar a los no cristianos la posibilidad de articular una ética social basada en un humanismo compasivo, pero esto no es necesariamente así, siempre que al problema del sufrimiento humano se le dé el lugar que le corresponde -el centro de la ética social一, y ello no sólo en la comunidad cristiana, sino también en nucstro mundo plural. El símbolo de la cruz plantea preguntas a las que todo ser humano, toda cultura y toda ética social, ya sea religiosa o secular, deben responder.

Como sostiene Michael Buckley, ningún tipo de humanismo puede hoy tener credibilidad si no ampliamos nuestra comprensión de modo que el humanisıno incluya no sólo celebrar la cima de las culturas, sino también la compasión ante los abismos de sufrimiento en los que pueden caer ${ }^{28}$. "Cambiar de tema" cuando se plantea la pregunta sobre el significado último de nuestra historia sangrienta es, sencillamente, insuficiente. Los seguidores de todas las religiones y los que no siguen ninguna de ellas deben afrontar las cuestiones que plantea esta historia.

Ello no significa que el humanismo que de ahí resulte tenga que ser explícitamente cristiano. Gandhi, por ejemplo, mantuvo su plena identidad hindú a pesar de reconocer que su encuentro con la cruz había afectado profundamente el modo de entender su propia religión. Creyó que Jesús "pertenece no sólo al cristianismo, sino al mundo entero"29. Gandhi, para su causa de la no violencia, hizo uso de un poema sobre la guerra, el "Bhagavad Gita", que lo releyó como parábola de no violencia y de solidaridad con los proscritos. Lo hizo inspirado en los movimientos de reforma al interior del hinduismo, pero también lo pudo hacer porque aprendió a leer el "Gita" bajo una luz nueva, al ponerlo en relación

28. Véase M. J. Buckley. "Christian humanism and Human Misery: A Challenge to the Jesuil university" en Francis M. Lazarus (ed.), Faish, Discovery, Service: Perspectives on Jesuit Education, Milwaukee, 1992, pp. 77-105.

29. Gandhi. The Law of Love, Anand T. Hingorani (ed.). Bharatiya Vidya Bhavan, 1962, p. I11. Citado en james W. Douglas, The Non-Violent Cross: A Theology of Revolution and Peace, Nueva York, 1968, p. 56. 
con la historia crisliana de la cruz. Y es que, si hemos de lograr hoy en día un humanismo y una élica social creibles, todas las interpretaciones de significado último han de hacerse presentes en una discusión libre y de gran aliento.

Lo que sí exige el tomar en serio la cruz es que el problema del sufrimiento humano sea abordado directamente por cualquier humanismo que tenga la pretensión de serlo. En consecuencia, la búsqueda de universalidad en el discurso ético significa que la realidad del sufrimiento humano, allí donde se da, debe ocupar un lugar central en la búsqueda de cualquier forma de moral común.

La cuestión final sigue siendo de carácter religioso, aquella que la muerte de Ellacuría y la del mismo Jesús siguen planteando. Ninguna de las dos ha acabado, de hecho, con la injusticia y el sufrimiento cotidiano de los crucificados de este mundo. La claridad intelectual y el realismo práctico nos obligan a reconocer que tampoco lograrán eliminarlo nuestros esfuerzos por aliviar este sufrimiento en una sociedad construida sobre principios de compasión, solidaridad y justicia en favor de los marginados.

Al llegar a esta situación límite nos quedan dos opciones. $\mathrm{O}$ bien llegamos a la conclusión de que nuestra incapacidad para eliminar el sufrimiento significa el fin del humanismo, o bien descubrimos una fuente de esperanza que pueda sustituir con ventaja nuestra capacidad de planificar, controlar y lograr éxitos. Este es el dilema postmoderno planteado en toda su profundidad. Porque desde mi punto de vista, cl dilema postmoderno tiene, en última instancia, un carácler religioso. La respuesta a la que apunta el signo de la cruz es que, de hecho, existe un poder mucho mayor que todo lo que nosotros somos capaces de concitar, y ese poder estriba en la solidaridad salvífica para con todos los que sufren, los abandonados, los que gritan "Dios mío, Dios mío, ¿por qué me has abandonado?" (Mc 15, 34).

Simone Weil trató el tipo de sufrimiento radical llamado aflicción. Cuando el sufrimiento nos parte el alma, decía Weil, entonces estamos "clavados al mismo centro del universo. Se trata del centro auténtico y no de una zona media; un centro que está más allá del espacio y el tiempo; que es Dios mismo... Ese centro se halla en la intersección de la creación y su creador. Y este punto de intersección es justamente el de los brazos de la cruz" 30 .

Cuando todo está dicho y hecho, es precisamente aqur donde podemos encontrar la fuente de un humanismo que pueda fundamentar una ética social de la compasión. Es aquí donde podremos descubrir una esperanza que no está basada en la ilusión de nuestro poder para controlar el mundo. Y cuando nos vemos obligados a elegir entre la desesperación o decir "en tus manos encomiendo mi espíritu" (Lc 23, 46), es aquí donde podemos encontrar la fuente más profunda

30. Simone Weil, Waiting for God. Nueva York, 1973, pp. 135-136. 
de energía para pensar y actuar en solidaridad con los que sufren.

Elegir entre la desesperación o la solidaridad no es algo que hagamos en circunstancias extremas, sino en la vida cotidiana, según vamos construyendo nuestra historia. Esta es la elección que, a mi juicio, aborda la élica bajo el signo de la cruz. Dicha ética responde y revela al mismo tiempo a un Dios que es Amigo, incluso en medio de las aflicciones de la historia. La cruz puede salvar las aspiraciones amenazadas del humanismo. La cruz puede hacer creible la esperanza cristiana en la resurrección y en la victoria final de la alegría. 